\title{
Less invasive coronary artery bypass grafting: without cardiopulmonary bypass and via reduced surgical access
}

The beating heart creates two formidable obstacles to coronary artery bypass grafting (CABG): the motion of the coronary target site hampers accurate anastomosis suturing; and, to reach posterior anastomosis sites, the beating heart needs to be dislocated which causes a precipitous drop in arterial pressure.

The use of cardiopulmonary bypass and crystalline cardioplegia provides the cardiac surgeon with a perfectly still surgical field, absence of blood in the target area, and freedom to manipulate the heart liberally to expose all major coronary branches. More than $99 \%$ of the current 800000 CABG procedures performed annually rely on cardiopulmonary bypass.

The morbidity and mortality of CABG is largely attributed to the use of cardiopulmonary bypass, global cardiac arrest, and hypothermia. ${ }^{1}$ Of particular concern are the adverse cerebral outcomes that affect $6 \%$ of patients. ${ }^{2}$ These are attributed to plaque emboli dislodged by manipulating the ascending aorta and to low perfusion pressure and/or microemboli resulting from the extracorporeal circulation. The trend to operate on progressively older patients is expected to magnify the problem of adverse cerebral outcome.

Other problems of cardiopulmonary bypass are the whole body inflammatory reaction and haemodilution; cardiopulmonary bypass requires full heparinisation; cardioplegic global cardiac arrest may temporarily depress myocardial contractility after restoration of coronary flow; hypothermia has an adverse effect on wound healing.

Remarkably, the strategy of the surgical procedure has remained essentially unchanged for more than 25 years.

\section{Alternative treatment strategies}

In the early 1990s, two developments initiated exploration of alternative treatment strategies for patients requiring CABG. First, CABG had been performed successfully without cardiopulmonary bypass for a decade in selected patients in two centres in South America ${ }^{34}$ resulting in an experience of more than 1000 cases in each centre. A promising report on low risk surgery on the beating heart for high risk patients was presented at the American Heart Association meeting in 1993.56 Second, minimally invasive surgery was extended to the chest.

Thoracoscopic surgery inspired the initiative at Stanford, California, USA in 1991 to develop closed chest, port-access, video assisted CABG on the arrested heart, using peripheral cannulation for the cardiopulmonary bypass. ${ }^{7}$ In our opinion, this strategy is unattractive because the major cause of procedure related morbidity and mortality remains an integral part of the approach.

\section{Less invasive CABG}

WITHOUT CARDIOPULMONARY BYPASS

The "invasive" nature of cardiopulmonary bypass implies that obviating the need for it is likely to be of major benefit to the patient. CABG on the beating heart, however, requires anastomosis site stabilisation. The use of traction sutures has yielded satisfactory results ${ }^{3-6}$ particularly in reoperations owing to motion reduction of adhesions. Suboptimal motion reduction, however, carries the risk of imperfect anastomosis suturing. Another risk is exerting too much traction on the proximal and distal coronary occlusion slings to improve coronary stabilisation. Too much traction might injure the coronary wall and result in focal stenosis owing to intimal hyperplasia.

\section{The coronary motion problem}

From 1993, renewed interest in the potential value of coronary surgery on the beating heart led to a fresh look at the coronary motion problem. One novel approach is to create periods of transient ventricular arrest pharmacologically. $^{8}$

An entirely different approach represents, conceptually, the opposite end of the technological complexity scale. By means of real time manipulation of thoracoscopic images, "virtual cardiac image arrest" is obtained. The algorithm which handles the digital image manipulation provides simultaneously the input to endoscopic robotic surgical instruments which track automatically the surgical target site on the beating heart. The surgeon looks at the video screen and observes a still target site and still endoscopic instruments, whereas in reality the coronary anastomosis site and the intrathoracic surgical instruments move together in space and time. By means of superimposed robotic surgery, the surgeon operates by conventional minimally invasive techniques on a virtually arrested target which in reality moves continuously. ${ }^{9}$ Such an approach is being pursued in the United States.

\section{Mechanical immobilisation aids}

Another approach is improvement of local coronary stabilisation by mechanical immobilisation devices. The most effective immobilisation will be obtained if the surgical area can be "arrested" locally by taking hold of adjacent epicardium and fixing it in space by a rigid connection to a stationary object-for example, the operating table, sternum retractor or rib retractor. ${ }^{10}$ The figure illustrates the motion reduction which may be obtained by this approach. This degree of motion reduction allows microsurgery on the beating heart. ${ }^{10}$ Taking hold of the epicardium on opposite sides of the coronary artery may be achieved by a suction device $(-400 \mathrm{~mm} \mathrm{Hg}$ ) nicknamed the "Octopus", which is suitable for open chest as well as closed chest immobilisation of the heart. ${ }^{10}$

The Octopus suction device also facilitates dislocation and rotation of the heart. Experimentally, it enables coronary surgery at the posterior side of the beating heart with the apex "pointing to the sky" manoeuvre to maintain arterial pressure. ${ }^{12}$ Initial clinical results in 70 selected patients operated since September 1995 are promising ${ }^{13}$ (limited access 40, 1.2 anastomoses 


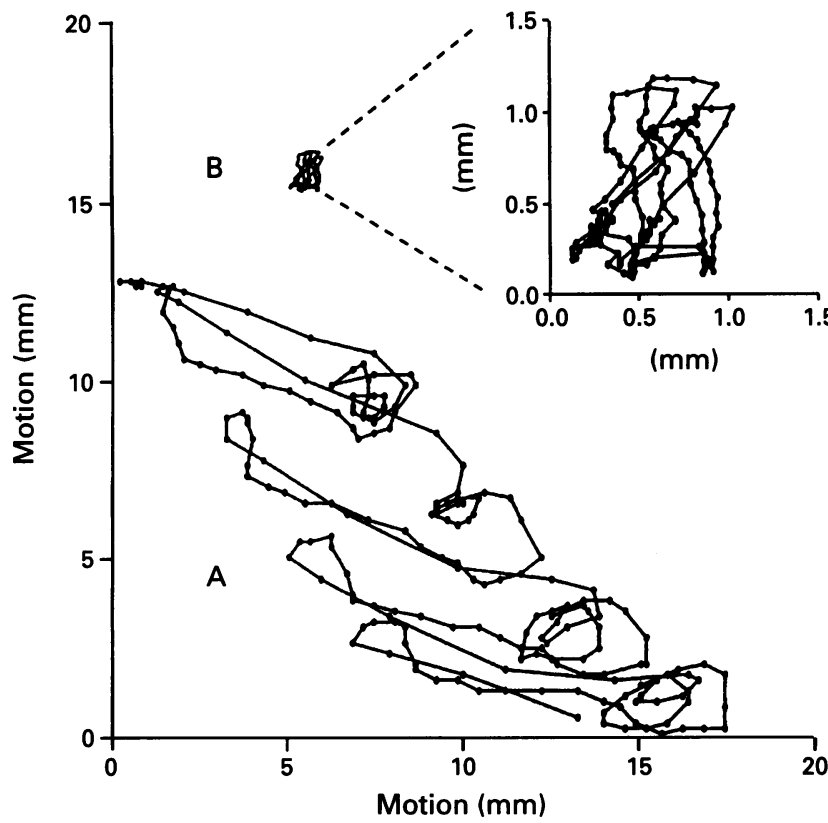

Example of two-dimensional motion of an epicardial beacon in the obtuse marginal branch area during an open chest procedure in a pig. Motion of the beacon was monitored during half a respiratory cycle when the heart was unrestrained $(A)$ and during local immobilisation by the "Octopus" (B). The inset shows an enlargement of the residual motion (B). Local motion is reduced to about $1 \times 1 \mathrm{~mm}$. Data points are separated by a 20 ms interval. Reproduced from J Am Coll Cardiol 1996;27:1356-64 with permission of the American College of Cardiology.

per patient; full access $30,2 \cdot 4$ anastomoses per patient) (Jansen et al, unpublished data). Several other local immobilisation devices have been developed recently, but they do not take hold of the epicardium actively by suction.

Because of the high grade proximal stenosis (or occlusion) with apparently well developed collateral flow, interruption of coronary flow for 10 to 20 minutes for anastomosis suturing is remarkably well tolerated. ${ }^{3-6}$ 13-15

CABG VIA REDUCED ACCESS OPENING

The full length median scar left on the front of the chest after median sternotomy may be disturbing, particularly in female patients. A rare, but serious complication of median sternotomy is sternal infection and dehiscence. ${ }^{1}$ If only a left internal mammary artery to left anterior descending coronary artery graft is needed, the limited anterolateral thoracotomy ("mini-thoracotomy") approach shows promising results and warrants further exploration of beating heart coronary surgery. ${ }^{13-16}$

Mobilisation of the full length internal mammary artery through a mini-thoracotomy is technically demanding. Some investigators employ thoracoscopic mobilisation of the proximal internal mammary artery and distal mobilisation by direct vision through the surgical wound.

\section{Terminology}

The current terminology is confusing. "Minimally invasive" in MICABG hardly ever implies video assisted. Portaccess is now used for a direct vision, oval port (mini-thoracotomy) approach. MIDCAB refers to minithoracotomy CABG (minimally invasive direct vision). Both technology and terminology are evolving. ${ }^{16}$
Less invasive arterial coronary revascularisation on the beating heart

The prospective of long lasting functional bypasses is excellent if arterial grafts only are used. In addition, manipulation of the ascending aorta is entirely avoided. CABG on the beating heart may reduce the hospital stay to about four days compared with a median stay of eight days after conventional CABG. ${ }^{2}$ Work and social activities may be resumed after two to three weeks rather than two to three months. These differences will mean a substantial reduction in costs.

In five years, the percentage of CABG patients treated by arterial grafting without cardiopulmonary bypass may be as high as $25-50 \%$. This development is likely to affect the decision on surgical versus interventional therapy of coronary artery disease. Professor Borst has received substantial financial support from the Netherlands Heart Foundation (grant 1993/43.028) and the Utrecht University Hospital (grant 1995/B903). Drs Borst and Jansen have a consultant agreement with Medtronic regarding "minimally invasive cardiac surgery". Medtronic has
acquired the patent rights on the "Octopus" method from the Utrecht acquired the patent rights on the "Octopus" method from the Utrech University and the Utrecht University Hospital. Comments on the manuscript
by prof.dr. JJ Bredée and prof.dr. EO Robles de Medina are gratefully acknowledged.

CORNELIUS BORST ERIK W L JANSEN

Heart Lung Institute,

Utrecht University Hospital,

Department of Cardiology, Room G02 523

PO Box 85500, 3508 GA Utrecht,

The Netherlands

e-mail: exp.cardio@hli.azu.nl

1 Kirklin JW, Barrat-Boyes BG. Cardiac surgery. Morphology, diagnostic criteria, natural history, techniques, results, and indications. 2nd ed. New York Churchill Livingstone, 1993:73-112, 143-7, 175-7, 286

2 Roach GW, Kanchuger M, Mangano CM, Newman M, Nussmeier N, Wolman $\mathrm{R}$, et al. Adverse cerebral outcomes after coronary bypass surgery. N Engl ₹ Med 1996;335:1857-63.

3 Benetti FJ, Naselli G, Wood M, Geffner L. Direct myocardial revascularization without extracorporeal circulation: experience in 700 patients. Chest 1991;100:312-16.

4 Buffolo E, De Andrade JCS, Branco JNR, Teles CA, Aguiar LF, Gomes WJ. Coronary artery bypass grafting without cardiopulmonary bypass. Ann Thorac Surg 1996;61:63-6.

5 Mohr R, Moshkovitz Y, Agranat O. Coronary artery bypass without cardiopulmonary bypass: low-risk surgery for high-risk patients [abstract] Circulation 1993;88:1637.

6 Moshkovitz Y, Lusky A, Mohr R. Coronary artery bypass without cardiopulmonary bypass: analysis of short-term and mid-term outcome in 220 patients. F Thorac Cardiovasc Surg 1995;110:979-87.

7 Stevens JH, Burdon TA, Peters WS, Siegel LC, Pompili MF, Vierra MA, al. Port-access coronary artery bypass grafting: a proposed surgical method. F Thorac Cardiovasc Surg 1996;111:567-73.

8 Robinson MC, Thielmeier KA, Hill B. Transient ventricular asystole using adenose during minimally invasive and open sternotomy coronary artery bypass grafting. Ann Thorac Surg. [In press.]

9 Borst C. US Patent Application 08/086,846: Robotic system for close inspection and remote treatment of moving parts (5 July 1993). Published as PCT Patent Application W095/01757 (19 January 1995)

10 Borst C, Jansen EWL, Tulleken CAF, Gründeman PF, Mansvelt Beck HJ, Van Dongen JWF, et al. Coronary artery bypass grafting without cardin Dongen J diopulmonary bypass and whout interruption of native coronary flow using a novel anastomosis

11 Jansen EWL, Gründeman PF, Mansvelt Beck HJ, Heijmen R, Borst C Experimental off-pump grafting of a circumflex branch via sternotomy usperimentaion a suction device. Ann Thorac Surg. [In press.]

12 Gründeman PF, Borst C, Van Herwaarden JA, Mansvelt Beck HJ, Jansen EWL. Hemodynamic changes during displacement of the beating heart by the Utrecht Octopus method. Ann of Thorac Surg. [In press.]

13 Jansen EWL, Gründeman PF, Borst C, Eefting FD, Wesenhagen $\mathrm{HH}_{\text {, }}$ Diephuis $\mathrm{J}$, et al. Less invasive coronary artery bypass grafting on the beating heart: initial clinical experience with the Utrecht "Octopus" method for regional cardiac wall immobilization [abstract]. Circulation 1996;94:I52.

14 Subramanian VA, Sani G, Benetti FJ, Calafiore AM. Minimally invasive coronary bypass surgery: a multi-center report of preliminary clinical experience [abstract]. Circulation 1995;92:1645.

15 Calafiore AM, Di Giammarco G, Teodori G, Bosco G, D'Annunzio E Barsotti $\mathrm{A}$, et al. Left anterior descending coronary artery grafting via left anterior small thoracotomy without cardiopulmonary bypass. Ann Thorac Surg 1996;61:1658-65.

16 Hartz RS. Minimally invasive heart surgery. Circulation 1996;94:2669-70. 